\title{
Polypharmacy, the ethical implication in the elderly
}

\author{
La polifarmacia, la implicación ética en el adulto mayor
}

\author{
Elena G. Olvera-Hernández ${ }^{a}$, María del Refugio Acuña-Gurrola ${ }^{b}$, Alejandro \\ Chehue-Romero $^{a}$
}

\begin{abstract}
:
Worldwide, the population has been aging, in 2015, life expectancy was 70.5 years old, with around $14 \%$ of the planet's inhabitants having an age of 60 years or more. While, for the same period (Organización de las Naciones Unidas, 2013). The average number of years was, in Mexico, 74.95, with $10.28 \%$ being part of this population group (Consejo Nacionacional de Población, 2019). In Mexico in 2016 it amounted to 12.4 million people over 60 years. For its part, in the State of Hidalgo, based on data taken from the Intercensal Survey conducted by the National Institute of Statistics and Geography, in 2015, $10.90 \%$ of the population exceeded 60 years, with a life expectancy of 74.46 years (Instituto Nacional de Estadística y Geografía, 2019).

However, greater life expectancy does not imply greater quality of life, that is, living longer is not associated with well-being, since currently the increase in longevity is accompanied by a higher incidence of morbidity and disabilities, directly related with geriatric medicine (Bagma, Griño, San José \& Armandons, 2010).
\end{abstract}

\section{Keywords:}

Polymedication, elderly, medication and chronic diseases

\section{Resumen:}

A nivel mundial la población ha estado envejeciendo, ya para el 2015 la esperanza de vida era de 70.5 años de edad, con lo que alrededor del $14 \%$ de los habitantes del planeta tenían una edad de 60 o más años (United Nations, 2013). Mientras que, para el mismo periodo, en México el promedio de años era de 74.95 , siendo el $10.28 \%$ parte de este grupo poblacional (Consejo Nacionacional de Población, 2019). En México en 2016 se ascendió a 12.4 millones de personas mayores de 60 años. Por su parte, en el Estado de Hidalgo, con base en datos retomados de la Encuesta Intercensal realizada por el Instituto Nacional de Estadística y Geografía, en 2015, el 10.90\% de la población sobrepasaba los 60 años, con una esperanza de vida de 74.46 años (Instituto Nacional de Estadística y Geografía, 2019).

Sin embargo, mayor expectativa de vida no implica mayor calidad de la misma, es decir, vivir más años no está asociado al bienestar, ya que en la actualidad el incremento de la longevidad se presenta acompañado de mayor incidencia de morbilidad e incapacidades, directamente relacionadas con la medicina geriátrica (Bagma, Griño, San José \& Armandons, 2010).

\section{Palabras Clave:}

Polimedicacion, adulto mayor, medicamento y enfermedades crónicas

\footnotetext{
a Correspondence Elena Guadalupe Olvera Hernández, Universidad Autónoma del Estado de Hidalgo, Instituto de Ciencias de la Salud, https://orcid.org/0000-0002-9704-4872, Email: olverae@uaeh.edu.mx.

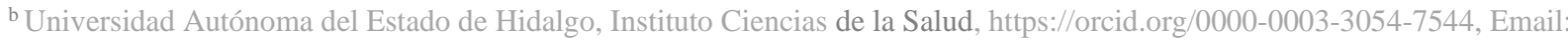
chehuea@uaeh.edu.mx.

c Universidad Autónoma del Estado de Hidalgo, Instituto de Ciencias de la Salud, https://orcid.org/0000-0003-3194-5392, Email:
} maria_acuna@uaeh.edu.mx. 


\section{INTRODUCTION}

The physiological process of aging increases the risk of developing chronic degenerative diseases and comorbidity due to the prevalence of multiple pathologies no transmissible chronic. Among the most common conditions in aging are: hearing loss, cataracts, refractive errors, back pain, neck pain, osteo-arthritis, neuropathies chronic obstructions, diabetes depression and dementia. Furthermore, there is a probability to experience various conditions at the same time or as it is known as Geriatric syndromes(World Health Organization; Zavala, Terán, Nava, Pineda \& Mata, 2018).

\section{POLYPHARMACY AND AGING}

A well-known situation are prescription cascades caused by medication side effects sometimes interpreted as a new disease, such as Parkinson's disease induced by antipsychotics or metoclopramide, or diarrhea and urinary incontinence induced by cholinesterase inhibitors (donecepil, rivastigmine, etc.), according to Diz-Loiz, Fernandez \& Perez, 2012).

A clear example of that, is the incidence of chronic noncommunicable diseases in Hidalgo State that means that close to $24.05 \%$ of Mexican older than 60 years old has been diagnosed with diabetes mellitus and $37.06 \%$ with high blood pressure. Meanwhile in Hidalguense larger population shows a sample of 2484 of elderly.

Evaluated in SABE-Hidalgo, it can be observed in chart 1, $45.7 \%$ of the people from 60 to 64 years report the diagnosis of

Systemic Hypertension, while 30.5\% suffer of type 2 Diabetes Mellitus, and whose percentage tends to rise with advancing age. Sanitary scientific researches, economic and social development in the last decades with the implementation of preventive measures have showed a better disease controls addressing to chronic diseases. As a result, an increased life expectancy, adding to morbidity, it has a direct impact on the increased consumption of sanitary resources and drugs. ${ }^{9,10}$.

If clinical practice guides are followed, the treatment given to a patient with multiple diseases implies multiple drugs and using non-pharmacological measures. Therefore, the profile of a polymedicated e patient would be of an elderly person who has multiple chronic diseases associated (González et al., 2017).

In this regard, polypharmacy is defined as the use of multiple drugs during a long term or at least during 6 months used by a patient and non-prescription drugs also must be included, as well as, supplements or vitamin complexes. As a consequence, it is vital to consider herbal remedies, at least some with significant biological activity for instance, sedative, laxative, excitant, anticholinergic, anabolic, etc, among others.
By doing so, the minimum number of drugs needed to define polypharmacy is debated controversially in the literature, with a range from three to six drugs, which the most extended is of five drugs used chronically ${ }^{9,7}$.

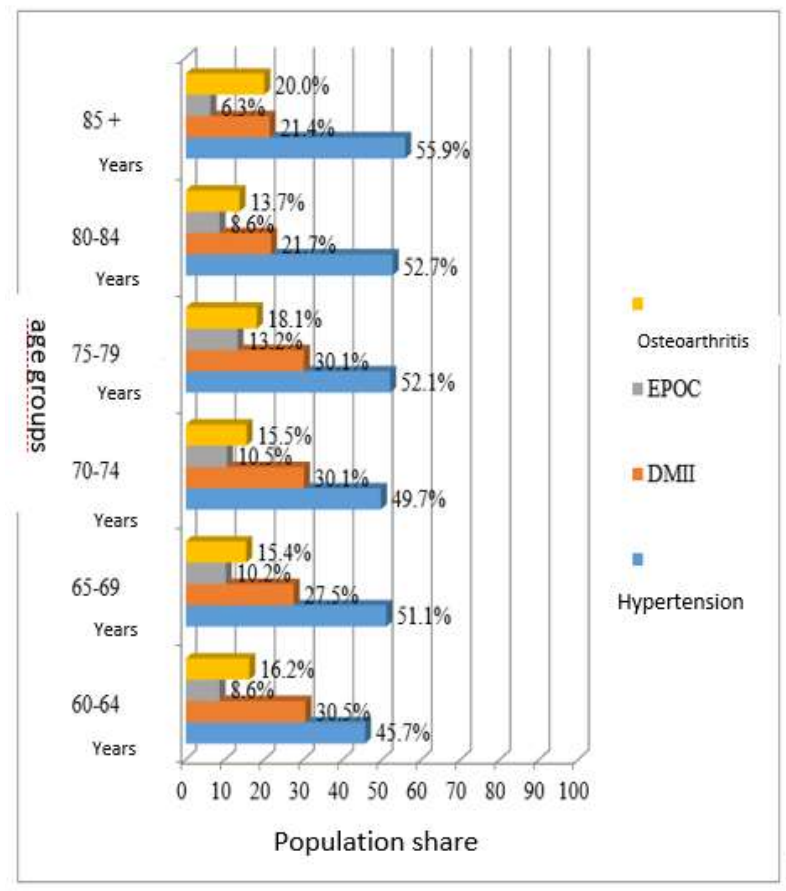

Graphic 1. Percentage of having chronic diseases in the elderly statewide population.

Source: Data taken from Health, Well-being and Aging Survey (SABE, 2016) from Hidalgo State.

Thus in a sample of 2599 elderly from Hidalgo, it is reported that a total consumption of 4868 drugs (allopathic and no allopathic) of which $32.8 \%$ of the drugs were taken by elderly who are not allopathic, followed by $22 \%$ of painkillers.

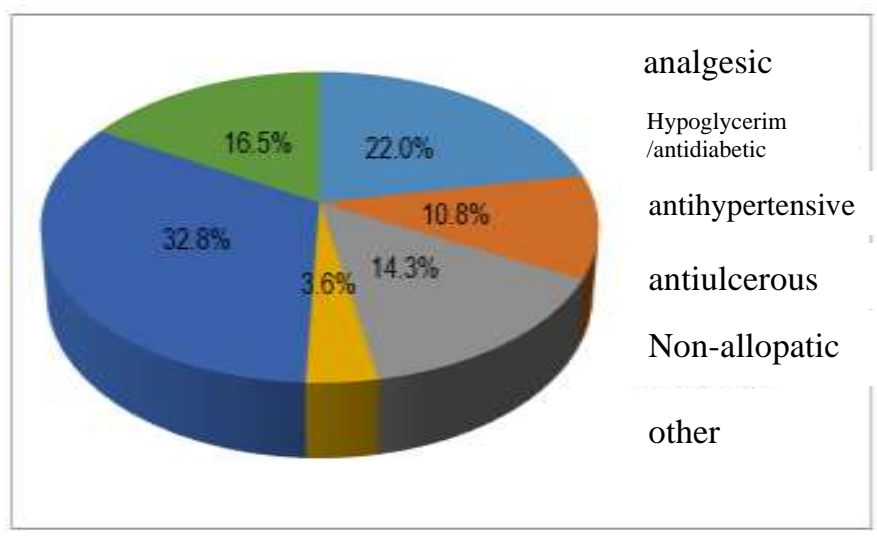

Chart 2.Percentage of the most frequent drug consumption in elderly population in Hidalgo.

Source: Own authorship, data taken from the database of the Health, Well-being and Aging Survey (SABE, 2016) from Hidalgo State. 
On one hand, multi-pathological patients are often elderly and consume a lot of drugs. Consequently, polypharmacy affects $85 \%$ of them and also there is no evidence of increased survival (González et al., 2017).

On the other hand, there is a higher prevalence of risk of polypharmacy in people from 60 or over this age, which is defined as concomitant use of multiple drugs that in some cases are needed to treat those patients with multiple pathologies

However, before adding to any drug to therapeutic regimen of an elderly, it is vital to analyze risk-benefit balance whose objective is to optimize pharmacological theraphy because of the potential presence of negative consequences of a person's health. In addition, therapeutic adherence decreases, as well as, inappropriate prescribing such as adverse drug reactions, interactions, hospitalizations, morbidity and mortality (MartinPérez, Lopez de Hernández, Hernández-Barrera, JiménesGarcía \&Jiménez-Trujillo, 2017).

Therefore, it is difficult to justify the necessity to take into account more than six active principles chronically, because this act itself corresponds to a new illness due to the risk of causing major toxic effects with that combination is high.

Thereupon, extensive population studies have showed that the frequency of adverse reactions to drugs is of 50 per each thousand people per year, which of them $0.7 \%$ are fatal, 8.9 are potentially fatal, $28.3 \%$ are serious and $62 \%$ are significant. So, the use of 6 or more drugs is a predictor of independent mortality (OR: 3 ) because the risk is logically proportional to the number of drugs taken regularly (DiazLopéz, Fernández \& Pérez, 2012).

As a matter of fact, elderly are susceptible to the effects of polypharmacy because of variation of pharmacodynamics,pharmacokinetics and reactions associated to medications(RAM), where physiological changes to pharmacokinetics cause a reduction of renal clearance and hepatic .Also, there is an increase in volume of distribution of liposoluble drugs and a variation in response of target organ damage, which are more sensible to diverse pharmacological groups such as cardiovascular drugs, anticoagulants and psychotropic(Gómez et al., 2017; Zavala, Teràn, Nava, Pineda \& Mata, 2018).

Thereon, from 4868 drugs taken by 2599 elderly in Hidalgo are used painkillers, hypoglycemic, antihypertensive drugs, antiulcerus drugs and other allopath drugs which are mainly prescribed by doctors from $81.0 \%$ to $89.5 \%$. Nevertheless, a high percentage of informers with a $58.8 \%$ mentioned that they self-medicate with no allopath drugs, as it shows the following chart.

On the basis of this percentage distribution of consumption and prescription, it is clear that doctors that care for elderly must be taught in a good practice of prescribing in order to prevent overmedication or to identify drug combinations that result in drug pharmaceutical interactions interactions. Refering to them, it has been described as the use of recommended drugs, specification of wrong medication, use of two or more drugs to treat the same disease or two or more drugs with the same therapeutic class. ${ }^{12,9}$.

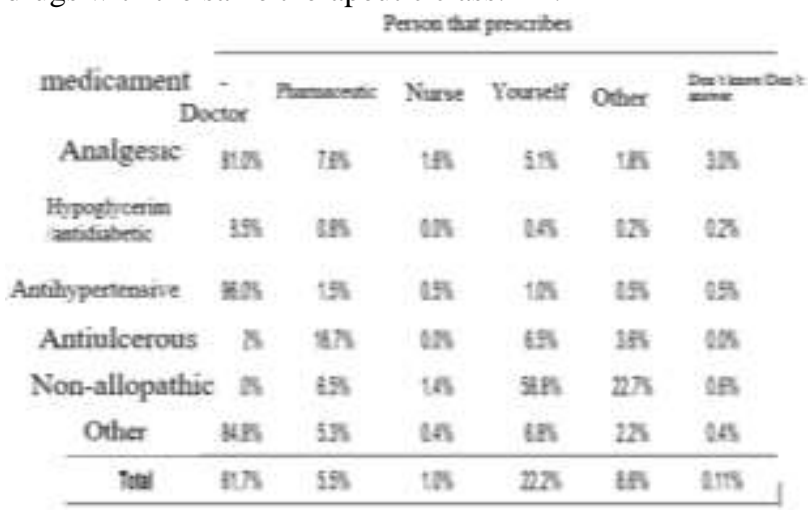

Chart 1.Percentage of taken drugs by elderly in Hidalgo

Source. Own authorship, data taken from database of Health, Well-being and Aging Survey (SABE, 2016) from Hidalgo State

As a conclusion, it is important to take into consideration risk/benefit balance of a prescribed drug in a given situation. Sometimes is necessary to sacrificing maximum effectiveness in a particular problem to avoid complications. For instance, digestive bleeding is being treated with dicumarinics in $\mathrm{AF}$ (atrial fibrillation)in which case a patient can stop treatment or maintain it with a suboptimal INR(International Normalized Ratio ).Furthermore, it can be considered as an option of stopping or minimizing dose of benzodiazepines to prevent relapses(Diaz-Lopez, Fernandez \& Pérez, 2012).

In the same way, other circumstances which doctor is prompted to prescribe are the following: fugacity in relation to the sick because it is easier to prescribe than to history, and the collaboration with the promotion of commercial drugs. On the part of the patient, multiple pathologies, a progressive loss of self-cares, an unhealthy life style, free medical care and medication. Furthermore, pharmaceutical industry related to the promotion in some cases excessive of products looking for the doctor's collaboration.

However, it is important to recognize that in many cases, a significant part of therapeutic armamentary is something new reason why the obtained information considering pharmaceutics industry and financed studies by the same. That causes a bias to prescribe without paying attention to the 
medical work caused by the industry included the continuous and regulated training and the collaboration with medical conferences (Diaz-Lopéz, Fernández \& Pérez, 2012).

On one side, the media also influences to the excessive and not clear publicity, as well as, the involuntary promotion of false expectative, causing an excess approval of similar assets of principles and genetic products without a clear or accurate references in relation to the use.

It is undoubted that any method that make prescriber look for the necessity to rationalize use of therapies is good to improve the quality of the treatment and it also decreases the secondary effects, but nothing can substitute as good anamnesis to prescribe well(Diaz-Lopéz, Fernàndez \& Pérez, 2012).

Apart from the foregoing, it mentions that when all the protagonists of the health care are oriented to the same direction, that is to say polypharmacy, it is hard to change this tendency because not only the doctor and the pharmaceutical participate but also the industry and the patient follow the same consumption route. To which it adds the fact of modern society that defines itself as well-being society, which favors and induces the consumption of goods and services .In addition, for this society is easier to take drugs to avoid osteoporosis or overweight than to practice physical activity regularly (Diaz-Lopez, Fernández \& Pérez, 2012).

\section{BIOETHICS AND MEDICATION MANAGEMENT TO THE ATTENTION OF THE ELDERLY}

The incorporation to the welfare ethics to the geriatric care start becoming something indispensable to a quality care, that care keeps the dignity of each one of the old people that are attended in the health social and sector.

Nevertheless, currently there is a situation of moral pluralism in which is not easy at all to come to an agreement about what must be done and what must not be done to assist the elderly. Bioethics has done a methodology that can help determine which the ethical minimum requirements to anyone are (professional, voluntary, politic and manager, etc) to the attendance of the elderly (Goikoetxea, 2013).

This methodology has been developed in our environment by the professor Diego Garcia Guillen and has three steps or moments:

Step 1 .Universal and formal principle (VALID to any human being and must be always respected)

Every human being must be treated with consideration and respect.
This principle is based on a certain conception of the human being that claims that he has dignity and no price and that respect to dignity is an absolute moral obligation.

Step 2.Universal material principles and no absolute (VALID to any human being, but there are exceptional circumstances in which is not compulsory to comply them)

Non-maleficence. Obligation of not hurting our existential practices to the physical or mental integrity of a user

Justice: obligation of not discriminating a person in terms of the resources disbursed.

Autonomy: obligation to respect values, ideas, beliefs and a user's life project.

Charity: obligation to do right of a person according to his/her own life project.

Step 3: value if according to the expected consequences, an exception can be done to the principles of step 2 .

The exceptions must be justified based on principle of step That is to say, a specific practice can be done that poses a risk of grave injury to a person, for example, let him/her living only despite of having high risk of a significant extent of deterioration. If it is the best way to respect his/her dignity and treat him/her with consideration and respect.

Scope of assistance (health and social sector) are private sectors. Due to the relations that we require to professionals of attention and assistance are of professional excellence that is why is important to demand that their decisions and actions are well-founded and motivated with the compromise of doing right and avoid violating privacy management and people's privacy, in this case of the elderly. As a result, as we can observe it is necessary to develop attitudes, abilities and virtues that promote a good treatment, especially in attention and care sectors to the most dependent and vulnerable people (Goikoetxea, 2013).

The principle of non-maleficence demands to the professional, formal and informal caregivers to get ready of knowledge, abilities and needed attitudes that are related to the dependent people, and in order to not injure his honor and dignity. For that purpose, the development and the monitoring of personalized good practices which with enough scientific evidence in the case of professionals improve the people's quality of life. The good treatment of the elderly requires that the research development and the development in the areas of Geriatrics and Gerontology, especially to those sectors in which are found special situations of deteriorating and dependence such as neurological diseases like dementias and processes of end of life (Goikoetxea Iturregui, 2013). 
As mentioned above, doctors who attend the elderly must improve themselves in the good practices of prescription in order to prevent overmedication or identify pharmacological combinations that result in pharmaco drug interactions (González, Veranes, García, \& Valdéz, 2012)Not only the doctor but also the other professionals that participate in medication,treatment and monitoring of the elderly.

As health professional, it must be taken into account that polypharmacy also includes medication given without medical prescription or supplements or complex vitamins, and herbal remedies among others.

A path should be avoided is to strengthen the presence of negative consequences for a person's health, thus increasing therapeutic adherence, reducing prescription potentially inappropriate causing adverse reactions to drugs, interactions, hospitalizations,morbility and also mortality. The ethic perspective claims that people make decisions and take actions that cause a greater possible benefit to human beings, starting from ourselves and focusing more when is a patient and even more if he is an elderly.

\section{REFERENCES}

Bagma, J., Griño, A., San José, A. \& Armandons, L. (2010). Comorbidity, hospital admission and drug consumption due to chronic disease not aggravated in the elderly population. Clín. Rev. Clín. 197, 472-478.

Diaz-Lopéz, M., Fernández, A., \& Pérez, V. (2012). The polymedicated patient. Galicia Clínica| Sociedad de Galega de Medicina Interna; 73(Supl. 1), S37-S41.

Goikoetxea, M. (2013). Ética y buen trato a personas mayores; Sociedad y Utopía. Revista de Ciencias Sociales, (41),424-448.

Gómez, A., Caudevilla, M., Bellostas, M., Crespo, M, Velilla, M., \& Díez-Manglano, J. (2017). Pluripathology, polypharmacy, therapeutic complexity and appropriate use of medication. Revista Clinica Española 217(5), 289-295. https://doi.org/10.1016/j.rce.2016.12.013

González, S., Veranes, A., Garcia, A. \&Valdéz, K. (2012). Nutritional status of older people in a health area of the municipality of Mariel. GeroInfo, 7(2), 1-18. doi:1816-8450.

Lago, J., Viveros, J. \& Heredia, J. (2012). Pharmaceutical spending in Spain. International Evolution, National Situation and Measures to Control Expenditure. Spain: School of Business Administration.

Martin-Pérez, M., López de Andrés, A., Hernández-Barrera, V., Jímenez-García, R., Jimémez-Trujillo, I., PalaciosCeña, D., \& Carrasco-Garrido, P. (2017). Prevalence of polypharmacy in the population over 65 in Spain: analysis of the National Health Surveys 2006 and
2011/12. Spain Journal of Geriatrics and Gerontology., 52(1), 2-8. doi:10.1016/j.regg.2016.07.006.

National Institute of Statistics and Geography. (Accesed August, 2017). Intecensal Survey. Available online: httpwww.beta.inegi.org.mxproyectosenchogaresespeci alesintercensal.

National Population Council, CONAPO. (Accessed February 2018). Projection Data. Accessed February 2017. Available online at: http://www.conapo.gob.mxesCONAPOProyecciones_ Datos

Secretariat of Health. Health Survey. (2016). Well-being and Ageing, SABE-Hidalgo. Mexico: Secretariat of Health; 2016.

United Nations, UN. (2013). World Population Prospects. The 2015 Revision. Key Findings and Advance Tables. New York: UN.

World Health Organization, WHO. (Accessed Aug. 2018). Ageing and health. Available online at https://www.who.int/es/news-room/factsheets/detail/envejecimiento-y-salud

Zavala, J, Terán, M., Nava, M., Pineda, M., \& Mata, M, (2018). Detection of polypharmacy and potentially inappropriate prescription in the elderly in a family medicine unit. Aten Far, 25(4),141-145. doi: http://dx.doi.org/10.22201/facmed.14058871p.2018.4.6 7257. 